\title{
Glass devices for efficient second harmonic generation
}

\author{
Fage-Pedersen, Jacob; Jacobsen, Rune Shim; Kristensen, Martin
}

Published in:

CLEO/Europe-EQEC 2005 Conference Digest CD

Link to article, DOI:

10.1109/CLEOE.2005.1568001

Publication date:

2005

Document Version

Publisher's PDF, also known as Version of record

Link back to DTU Orbit

Citation (APA):

Fage-Pedersen, J., Jacobsen, R. S., \& Kristensen, M. (2005). Glass devices for efficient second harmonic generation. In CLEO/Europe-EQEC 2005 Conference Digest CD: Europhysics Conference Abstracts (Vol. vol. 29B, pp. CD4-2-MON). IEEE. https://doi.org/10.1109/CLEOE.2005.1568001

\section{General rights}

Copyright and moral rights for the publications made accessible in the public portal are retained by the authors and/or other copyright owners and it is a condition of accessing publications that users recognise and abide by the legal requirements associated with these rights.

- Users may download and print one copy of any publication from the public portal for the purpose of private study or research.

- You may not further distribute the material or use it for any profit-making activity or commercial gain

- You may freely distribute the URL identifying the publication in the public portal

If you believe that this document breaches copyright please contact us providing details, and we will remove access to the work immediately and investigate your claim 


\title{
Glass devices for efficient second harmonic generation
}

\author{
Jacob Fage-Pedersen and Rune Jacobsen \\ Research Center COM, Technical University of Denmark, Building 345V, DK-2800 Kgs. Lyngby, Denmark. \\ Martin Kristensen \\ Department of Physics and Astronomy, University of Aarhus, Ny Munkegade, DK-8000 Århus C, Denmark
}

Owing to the well-established CMOS processing technology, silica-on-silicon has become an advanced platform for cheap and robust, mass-fabricated integrated optics. Passive components, multiplexers, rare-earth doped lasers, and thermooptic switches have been commercially produced, but it is highly desirable to extend the platform to include devices with nonlinear functionality. We show here that quasi-phase matched (QPM) planar nonlinear devices of high quality can be fabricated by means of periodic poling of the glass. The devices, used for second-harmonic generation (SHG), have accurately-controlled centre wavelengths, and the normalised conversion efficiencies are approximately one order of magnitude higher than what has previously been reported for periodically poled glass [1].

The devices are fabricated on low-resistivity silicon wafers. In typical batches, a thermal oxide is used as a lower cladding, and plasma-enhanced chemical vapour deposition is used to fabricate a silicon-oxynitride ( $\mathrm{SiON}$ ) core layer and a borophosphosilicate glass (BPSG) top cladding layer. Before deposition of the top cladding, waveguides are defined by etching a ridge into the core layer with the use of reactive ion etching. Periodic electrodes of $\mathrm{Al}$ are evaporated onto the surface of the top cladding, and the structure is finally sealed with a few $\mu \mathrm{m}$ of glass deposited on the top surface. The poling is typically performed in air, by heating up the device to $365^{\circ} \mathrm{C}$ for 15 minutes, with $+2500 \mathrm{~V}$ on the periodic electrode and the silicon substrate being grounded. The SHG measurements are performed by using a tuneable CW Ti:sapphire laser and collecting the SH intensity in a spectrum analyser.

In Fig. 1 we show a typical QPM spectrum from one of the poled devices. The measured spectrum agrees very well with the calculated spectrum, for which we used a squared sinc function with $\Delta k=k_{2 \omega}-2 k_{\omega}$ calculated from the Sellmeyer equation and

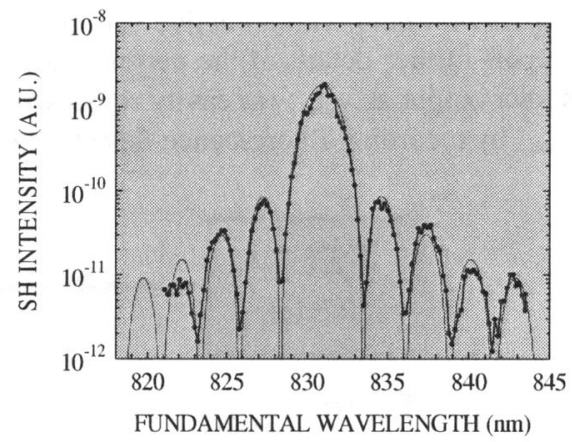

Figure 1. SH intensity vs. wavelength of the pump light in a 3-mm long device. Both measured points and a calculated curve are shown.

effective-index simulations. This shows that the devices have excellent uniformity along their full length. Devices of length up to $9 \mathrm{~mm}$ were fabricated and are found to exhibit perfect QPM curves. The waveguide geometry enables high optical confinement and good overlap with the nonlinearity induced by poling. Thus, in the batches with most optimum waveguide design, we obtain a maximum, normalised conversion efficiency of $1.4 \times 10^{-3} \% / \mathrm{W} / \mathrm{cm}^{2}$, which is roughly one order of magnitude higher than what has hitherto been demonstrated with periodic poling [1]. Conversion efficiencies of this order of magnitude will allow efficient doubling of pulsed laser sources with high peak powers. The periodically modulated (exploited) part of the nonlinear susceptibility is $\chi_{\text {expl }}^{(2)} \approx 0.13 \mathrm{pm} / \mathrm{V}$, and we believe an even higher value can be achieved. The value of the conversion efficiency decays somewhat with time; this is due to interaction with charges from the atmosphere and can be avoided by use of a high-quality sealing of the top surface of the device.

In Fig. 2 we show measured and calculated centre wavelengths of a set of QPM devices with electrodes of different period, ranging from $17 \mu \mathrm{m}$ to $25 \mu \mathrm{m}$. The calculations are based on the Sellmeyer equation and effective-index simulations. Over more than $120 \mathrm{~nm}$, both experimental and calculated points fall extremely close to the same curve. The typical, measured deviceto-device variation is less than $0.2 \mathrm{~nm}$, demonstrating a very high device-to-device uniformity across the size of the wafer.

In conclusion, we have demonstrated that high-quality nonlinear QPM devices can be fabricated in glass-on-silicon. The technology is easily adaptable to any desired wavelength (e.g. $1550 \mathrm{~nm}$ ) and can be used not only for SHG, but for wavelength conversion processes in general.

[1] V. Pruneri, G. Bonfrate, P.G. Kazansky et al: Greater than $20 \%$ efficient frequency doubling of 1532-nm ns pulses in quasi-phasematched germanosilicate optical fibers, Opt. Lett. 24 (4), 208 (1999).

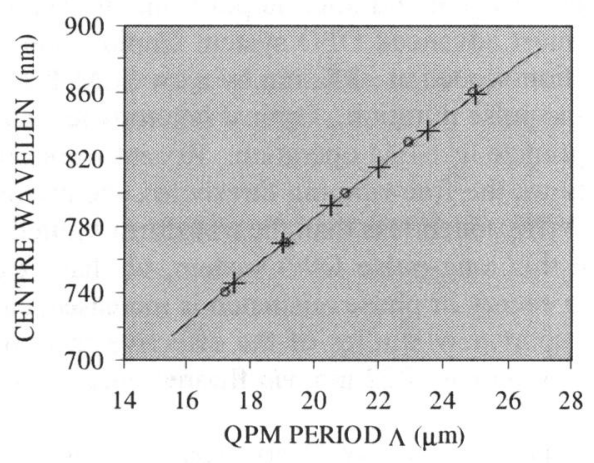

Figure 2. Centre wavelength of QPM devices vs. the period of the electrode. Both measured (+) and calculated (o) points are shown. The curve is a $2^{\text {nd }}$ order polynomial fit to the measured points. 